\title{
Paracoccidioidomicose primária de pálpebra e conjuntiva
}

\author{
Primary paracoccidioidomycosisof eyelid and conjunctiva
}

\author{
Ezon Ferraz ${ }^{1}$ \\ Wener Cella ${ }^{1}$ \\ Eduardo Rocha ${ }^{2}$ \\ Roberto Caldato ${ }^{3}$
}

Hospital das Clínicas da Universidade Estadual de Campinas - UNICAMP - Faculdade de Ciências Médicas Disciplina de Oftalmologia, Setor de Plástica Ocular.

${ }^{1}$ Residente de Oftalmologia da Universidade Estadual de Campinas - UNICAMP (SP).

2 Médico voluntário da Disciplina de Oftalmologia da Universidade Estadual de Campinas UNICAMP (SP).

3 Chefe do Setor de Plástica Ocular da Disciplina de Oftalmologia da Universidade Estadual de Campinas UNICAMP (SP).

Endereço para correspondência: Ezon Ferraz, R. Hermantino Coelho, 77/71, BL. 1 - Mansões Santo Antônio - Campinas (SP) CEP 13087-500. E-mail: ezon@uol.com.br

\section{RESUMO}

A paracoccidioidomicose (Pbmicose) é a micose profunda mais freqüente no Brasil, mas o acometimento ocular é raro e, quando presente, geralmente secundário. Os autores relatam caso de Pbmicose pálpebroconjuntival em que não foi encontrado foco extra-ocular. É feita uma revisão da literatura e discutida a importância da suspeita diagnóstica em população de risco e do tratamento precoce desta condição para o bom prognóstico visual.

Descritores: Paracoccidioidomicose/diagnóstico; Pálpebras; Conjuntiva/patologia; Doenças palpebrais

\section{INTRODUÇÃ̃O}

Paracoccidioidomicose $\mathrm{e}^{(1-3)}$ (Pbmicose) é doença sistêmica crônica causada pelo fungo dimórfico Paracoccidioides brasiliensis ${ }^{(4-5)}$. Também chamada de blastomicose sul-americana, foi descrita pela primeira vez por Adolfo Lutz em 1908, sendo o Brasil considerado área endêmica, acometendo tipicamente trabalhadores rurais do sexo masculino com faixa etária entre 30 e $60 \operatorname{anos}^{(3-5)}$.

$\mathrm{O}$ fungo encontra-se na sua forma esporulada à temperatura ambiente $\mathrm{e}$ tem como reservatórios e fontes de contaminação o solo, a madeira e a poeira $^{(3)}$. As portas de entrada aceitas para a infecção são a respiratória, tegumentar, digestiva e amigdaliana, sendo a primeira a mais freqüente e, por isso, o pulmão o órgão mais atingido por esta micose profunda ${ }^{(3-4)}$.

$\mathrm{O}$ acometimento ocular é infreqüente, com raras descrições na literatura de casos em topografia palpebral, conjuntival, corneana, uveal, coriorretiniana e orbitária ${ }^{(4)}$. O diagnóstico precoce assume importância por evitar a evolução da infecção para lesões mutilantes e cegueira ${ }^{(5)}$.

\section{MÉTODOS}

VAS, 49 anos, sexo masculino, pedreiro, procedente de Minas Gerais, procurou o Serviço de Oftalmologia da UNICAMP com queixa de prurido, dor, secreção purulenta e diminuição da acuidade visual no olho esquerdo há 6 meses. O quadro era insidioso e refratário a tratamentos prévios direcionados a uma provável etiologia bacteriana. Negava trauma ocular e alterações sistêmicas. Ao exame oftalmológico, apresentava acuidade visual sem correção de 0,8 no olho direito e 0,3 no esquerdo. A biomicroscopia mostrou olho esquerdo com edema inflamatório bipalpebral, de consistência firme e sem limites precisos que atingia toda a extensão das pálpebras, coloboma em pálpebra superior com margens necróticas e madarose associada, secreção purulenta acumulada em fórnice conjunti- 
val inferior, hiperemia conjuntival difusa moderada com quemose perilimbar e córnea transparente (Figura 1). O restante do exame era normal. A cultura da secreção conjuntival foi positiva para estafilococo coagulase-negativo e negativa para fungos. O anátomo-patológico da pálpebra inferior e conjuntiva evidenciou o processo de cripto-esporulação fúngica (coloração de Grocott), patognomônico de infecção pelo Paracoccidioides brasiliensis (Figura 2). Com o diagnóstico de Paracoccidioidomicose pálpebro-conjuntival, o paciente foi investigado de forma sistêmica para detecção de outros possíveis focos de envolvimento. $\mathrm{O}$ exame físico geral mostrou-se normal, assim com os exames laboratoriais, a saber: velocidade de hemossedimentação $=2 \mathrm{~mm}$ na $1^{\text {a }}$ hora, série eritrocítica $=5,37 \times 10^{6}$, leucócitos totais $=9,31 \times 10^{3}$, segmenta$\operatorname{dos}=3,16 \times 10^{3}$, linfócitos $=2,88 \times 10^{3}$, monócitos $=1,21 \times 10^{3}$, eosinófilos $=2,04 \times 10^{3}$, plaquetas $=220 \times 10^{3}$. A sorologia para paracoccidioidomicose por imunodifusão radial dupla foi reagente, com resultado de $1 / 1$ (normal = não reagente). Radiografia de tórax e ultra-sonografia abdominal não mostraram

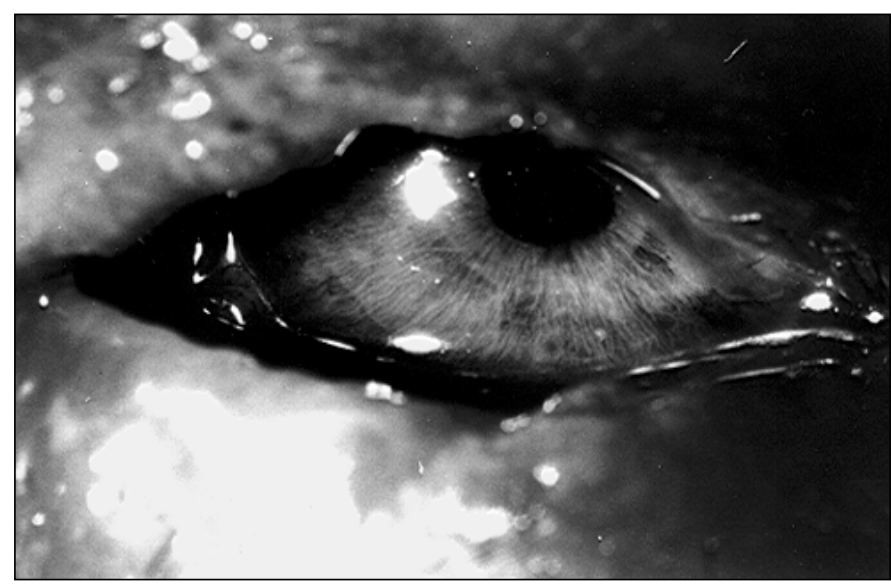

Figura 1 - Aspecto ocular da infecção no momento do diagnóstico (olho esquerdo)

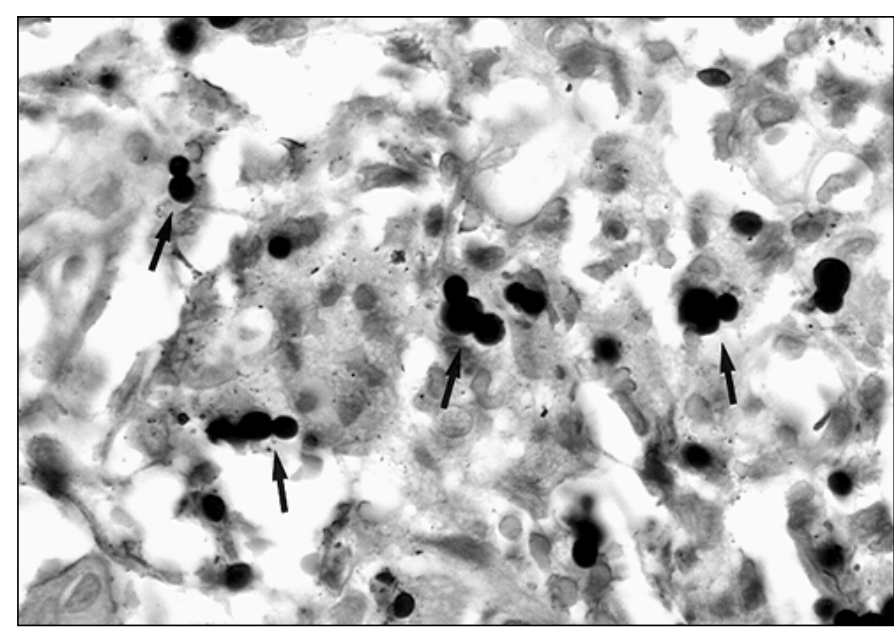

Figura 2 - Microscopia mostrando a cripto-esporulação do $P$. brasiliensis (setas) (Grocott) alterações. Foi iniciado esquema terapêutico com Sulfametoxazol (2,4g/dia) e Trimetoprima (480mg/dia) por via oral, associada a limpeza mecânica ocular com solução fisiológica estéril. Após duas semanas de tratamento o paciente referia melhora importante do edema e negava dor e prurido, apresentando ao exame do olho esquerdo edema bipalpebral discreto, hiperemia conjuntival leve e pequena quantidade de secreção purulenta em fórnice conjuntival inferior. O paciente foi orientado a manter o tratamento por um período de dois meses e retornar para cirurgia palpebral reconstrutora, mas perdeu o seguimento ambulatorial. Após 1 ano voltou ao serviço apresentando entrópio palpebral cicatricial e triquíase no olho previamente acometido. A triquíase resultou em perfuração corneana com intensa desorganização do segmento anterior. Como apresentava visão sem percepção luminosa e olho doloroso, foi indicada evisceração. Pela acentuada degradação tissular, o conteúdo ocular eviscerado não foi encaminhado para exame histopatológico.

\section{DISCUSSÃO}

A Pbmicose atinge principalmente os pulmões, o tegumento e os órgãos linfáticos ${ }^{(1,5)}$. Encontra-se diretamente relacionada ao fator ocupacional, sendo mais freqüentemente encontrada nos pacientes que trabalham em íntimo contato com o solo ou poeira, especialmente em áreas rurais, fato que reflete sua maior prevalência no sexo masculino ${ }^{(3,5)}$.

$\mathrm{O}$ acometimento ocular pela Pbmicose é raro mas, quando presente, pode causar lesões mutilantes e mesmo cegueira ${ }^{(5)}$ Belfort Jr. e col. (1975) descreveram as alterações pálpebroconjuntivais mais encontradas, consistindo de lesões ulceradas granulomatosas com fundo hemorrágico nas pálpebras, podendo atingir os ductos lacrimais; associam-se edema palpebral, hiperemia e, por vezes, um coloboma secundário à destruição tissular local. A conjuntiva apresenta-se difusamente hiperemiada e a presença de secreção purulenta devido à infecção secundária é observada com certa freqüência; lesões granulomatosas e hemorrágicas com estruturas foliculares também podem ser encontradas na conjuntiva ${ }^{(1,4)}$. Linfadenomegalias indolores cervicais, pré-auriculares e submandibulares também podem fazer parte do quadro ${ }^{(3,6-7)}$. Mais raramente, o trato uveal posterior é acometido, com lesões granulomatosas exsudativas, vascularização e periflebite. A coroidite pelo $P$. brasiliensis é descrita em pacientes imunocomprometidos, sendo este fungo um dos responsáveis pelas micoses oculares oportunistas ${ }^{(2)}$.

As lesões oculares por Pbmicose geralmente são secundárias, regredindo com a terapêutica sistêmica instituída para o foco primário ${ }^{(1)}$. Os esquemas terapêuticos não são unificados, observando-se na literatura casos de cura com sulfonamidas, cetoconazol e anfotericina $\mathrm{B}^{(5-6)}$. As hipóteses de envolvimento ocular compreendem a disseminação hematogênica do fungo e, mais raramente, inoculação direta no olho, quando limitada a este e geralmente precedida de trauma $a^{(1,5)}$. 
O diagnóstico definitivo é feito através de pesquisa direta do fungo, exame de cultura ou biópsia da região afetada ${ }^{(3,5-6)}$.

O presente caso mostra um envolvimento primário da pálpebra e conjuntiva, já que o exame geral do paciente não localizou focos extra-oculares da micose. O tratamento instituído, à base de sulfonamida sistêmica e limpeza mecânica local, mostrou-se eficiente imediatamente após sua instituição, mas deve ser complementado com a correção estética e funcional da pálpebra acometida. A cirurgia plástica reconstrutora se impõe com o objetivo de evitar o desenvolvimento de alterações secundárias a triquíase ou exposição excessiva do globo ocular. A perpetuação destas alterações, como aqui exemplificado, pode resultar em dano visual irreversível.

Por ser o Brasil região endêmica de Pbmicose, deve-se sempre suspeitar do envolvimento ocular por esta infecção em pacientes com evolução crônica que apresentam as características previamente descritas, principalmente se apresentarem risco ocupacional, idade superior a 30 anos e história pregressa desta infecção ${ }^{(5)}$.

\section{ABSTRACT}

Paracoccidioidomycosis is the most frequent systemic mycosis in Brazil, but ocular involvement is rare and, if present, often secondary to another site. The authors report a case of paracoccidioidomycosis of eyelid and conjunctiva where no extraocular focus was found. A brief review of the literature is made discussing the importance of diagnostic suspecion in a population at risk and early treatment for a good visual prognosis.

Keywords: Paracoccidioidomycosis/diagnosis; Eyelid; Conjunctiva/pathology; Eyelid diseases

\section{REFERÊNCIAS}

1. Belfort Jr R, Fischman O, de Camargo ZP, Almada A. Paracoccidioidomycosis with palpebral and conjunctival involvement. Mycopathologia 1975; $56: 21-4$

2. Hadmdan J, Guimarães IS, Oréfice F. Uveítes fúngicas. In: Oréfice F. Uveíte clínica e cirúrgica, Rio de Janeiro: Cultura Médica; 2000. p. 571-92.

3. Jannke HA, Lopez FS, Abrahão MC, Thofem P, Duarte AL, Holthausen ET. Blastomicose sulamericana palpebral. Rev Bras Oftalmol 1983;42:157-60.

4. Kamegasawa A, Moraes-Silva MRB, Franco M, Heimbeck FJ. Paracoccidioidomicose ocular: revisão. Arq Bras Oftalmol 1988;51:183-5.

5. Silva MR, Mendes RP, Lastória JC, Barravieira B, Marques AS, Kamegasawa A. Paracoccidioidomycosis: study of six cases with ocular involvement. Mycopathologia 1988;102:87-96.

6. Queiroz S. Blastomicose palpebral. Bol Soc Med Cir (Campinas) 1943:130

7. Sales M, Queiroz S. Blastomicose ocular (palpebral). Arq Inst Penido Burnier 1945;7:260-1.

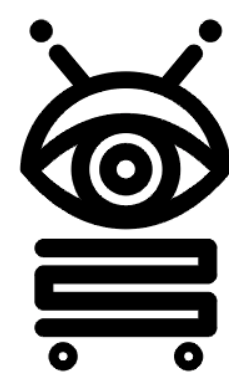

\title{
XXXI CONGRESSO BRASILEIRO DE OFTALMOLOGIA
}

\author{
5 A 9 DE SETEMBRO DE 2001
}

\author{
SÃO PAULO • SP
}

CENTRO DE CONVENÇÕES IMIGRANTES

\section{O LOCAL DO CONGRESSO:}

O Centro de Convenções Imigrantes é hoje um dos maiores centros de convenções da América Latina, com uma área coberta de 32 mil metros quadrados e uma área externa de 40 mil metros quadrados.

LOCALIZAÇÃO PRIVILEGIADA:

- 1 Km da Estação Jabaquara do metrô

- $7 \mathrm{~km}$ do Aeroporto de Congonhas

- $10 \mathrm{Km}$ da região hoteleira da Avenida Paulista 